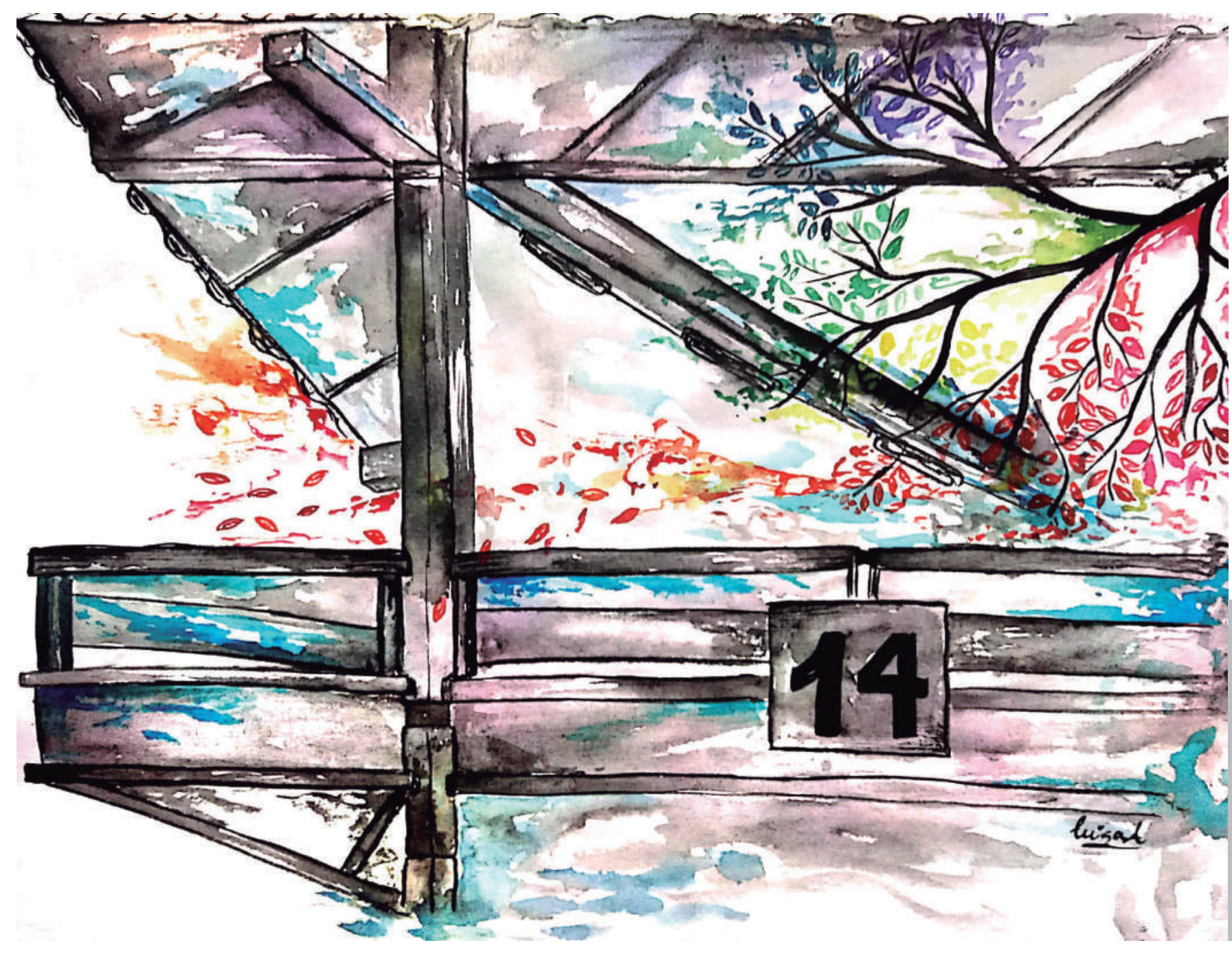

Sin título De la serie Memorias acuareladas Universidad de Antioquia Acuarela. $30 \times 25 \mathrm{~cm}$ 2019, Medellín 


\title{
Los principios rectores de política pública de acceso y equidad como dimensiones de red de política pública de las TIC en Colombia 2009-2018*
}

\author{
Raúl Andrés Tabarquino Muñoz (Colombia)**
}

\section{Resumen}

El artículo aborda la política pública de regulación del servicio público de las tecnologías de la información y las comunicaciones (TIC) en Colombia en el periodo 2009-2018, centrándose en la dinámica y estructura de los principios rectores de política pública de acceso y equidad como dimensiones de red de política pública. La metodología es mixta, utilizando el enfoque del análisis de redes sociales (ANR) en cuanto a consolidación de actores y análisis de la estructura en red. Los resultados demuestran que el principio rector de acceso es de mayor relevancia para la estructura en red de la política pública de TIC en Colombia que el de equidad, sustentado en la relación sumamente desigual entre control de la infraestructura y los servicios.

\section{Palabras clave}

Políticas Públicas; Análisis de Redes; Tecnologías de la Información y las Comunicaciones (TIC); Gobernabilidad; Colombia.

Fecha de recepción: octubre de 2018 - Fecha de aprobación: marzo de 2019

\section{Cómo citar este artículo}

Tabarquino Muñoz, Raúl Andrés. (2019). Los principios rectores de política pública de acceso y equidad como dimensiones de red de política pública de las TIC en Colombia 2009-2018. Estudios Políticos (Universidad de Antioquia), 55, pp. 112-139. http://doi.org/10.17533/udea.espo.n55a06

\footnotetext{
* Este artículo es producto del desarrollo de la línea de investigación en Análisis de redes y métodos cuantitativos del grupo Gestión y Políticas Públicas (Categoría A) de la Universidad del Valle, Colombia.

** Economista. Magíster en Políticas Públicas. Doctor en Administración. Director e Investigador del Grupo Gestión y Políticas Públicas, Categoría A de Colciencias, y docente de tiempo completo, Universidad del Valle, Colombia. Correo electrónico: raul.tabarquino@correounivalle.edu.co - Orcid: https://orcid.org/0000-0002-7866-1875
} 


\title{
The Guiding Principles of the Public Policy of Access and Equity as Dimensions of the Public Policy Network of ICT in Colombia 2009-2018
}

\begin{abstract}
The research deals with the public policy of regulation of the public service of Information and Communication Technologies (ICTs) in Colombia during the period 2009-2018; focusing on the dynamics and structure of the guiding principles of public policy of Access and Equity as dimensions of the public policy network. The analysis uses a mixed methodology, based on the approach of social network analysis (ARS) in terms of stakeholder consolidation and network structure analysis. The results show that the guiding principle of access is of greater relevance for the network structure of the public policy of ICTs in Colombia than the guiding principle of equity, based on the extremely unequal relationship between control of infrastructure and services.
\end{abstract}

\section{Keywords}

Public Policies; Network Analysis; Information and Communication Technologies (ICTs); Governance; Colombia. 


\section{Introducción}

El Estado colombiano ha adecuado sus capacidades funcionales e institucionales para el sector de las tecnologías de la información y las comunicaciones (TIC) a partir de 2009, integrando las telecomunicaciones y la informática como sector y servicio público mediante la expedición de la Ley 1341 de 2009 — Ley de Convergencia o Ley de TIC_-, generando entes reguladores especializados como: a) el Ministerio de las TIC (MinTIC); b) la Comisión de Regulación de Comunicaciones (CRC); c) la Agencia Nacional del Espectro (ANE); d) Agencia Nacional de Televisión (ANTV); e) la Subdirección de Telecomunicaciones del Departamento Nacional de Planeación (DNP); f) el Viceministerio de la Economía Digital; y g) la Superintendencia de Industria y Comercio (SIC), para un papel más activo en el proceso de control y trasparecían del servicio público (Tabarquino, 2018; OCDE, 2015; 2014; Valencia, 2015; Guerra y Oviedo, 2011).

El anterior esquema evidencia que el sector de las TIC en Colombia entre 2009 y 2018, a) evoluciona con el fin de dar respuesta a la tendencia mundial de la convergencia tecnológica —optimización de redes, aplicaciones

[114] y generación de contenidos digitales-, pasando de un servicio público domiciliario aun servicio público no domiciliario (Tabarquino, 2018; Varela, 2015; Valencia, 2015); y b) las políticas públicas regulatorias del sector han respondido a los retos planteados por el mercado y las innovaciones tecnológicas, pasando de una regulación basada en infraestructura a una regulación por servicios y luego a una regulación por mercados (Tabarquino, 2018; OECD, 2016; Katz, 2015).

Por lo anterior, es pertinente analizar el proceso de la política pública de regulación del servicio público de las TIC en Colombia 2009-2018, mediante el enfoque de redes porque: a) «La teoría de redes, además de entregar un mapa de todos los actores involucrados, permite detectar los obstáculos, los nudos o los puntos problemáticos» (Barozet, 2002, p. 31); b) la política pública de regulación del servicio público de las TIC en Colombia 2009-2018, contiene un alto grado de complejidad, sustentado en la interrelación de recursos con las cuales los actores establecen vínculos sectoriales en la red, definen de manera específica el rol en el sector y la subredes al interior de la política; y c) el fenómeno que se pretende describir no ha sido abordado por la literatura de manera extensa, de tal manera que el propósito es generar hipótesis de 
Los principios rectores de política pública de acceso y equidad como dimensiones...

trabajo que abran la puerta a la comprensión del fenómeno, dando luces para nuevas investigaciones en el ámbito del análisis de política pública.

Cuadro 1. Políticas públicas regulatorias del sector de las TIC en Colombia, 2009-2018.

\begin{tabular}{|c|l|}
\hline \multicolumn{2}{|c|}{ Integración telecomunicaciones e informática como sector y servicio público de TIC } \\
\hline $\mathbf{2 0 0 9}$ & $\begin{array}{l}\text { * Ley } 1341 \text { del } 30 \text { de julio de } 2009 \text {-Ley TIC o Ley de Convergencia-: i) define } \\
\text { los principios y conceptos en lo concerniente a la sociedad de la información y la } \\
\text { organización de las tecnologías de la información y las comunicaciones (TIC), y ii) } \\
\text { crea la Agencia Nacional del Espectro. } \\
\text { * La Comisión de Regulación de las Telecomunicaciones (CRT) se transforma en la } \\
\text { Comisión de Regulación de Comunicaciones (CRC). }\end{array}$ \\
\hline $\mathbf{2 0 1 1}$ & $\begin{array}{l}\text { * Decreto Ley 4169, entrega las funciones de planeación y atribución del espectro y } \\
\text { la actualización de bandas de frecuencia a la Agencia Nacional de Espectro (ANE) } \\
\text { * Resolución CRC 3066, regula los derechos de los usuarios de los servicios de } \\
\text { telecomunicaciones. } \\
\text { * Resolución CRC 3067, regula los indicadores de calidad para los servicios de } \\
\text { telecomunicaciones. } \\
\text { * Resolución CRC 3501, determina las condiciones de acceso para proveedores de } \\
\text { SMS y MMS. } \\
\text { * Implementación el plan Vive Digital 2011, que tiene como finalidad : i) masificar } \\
\text { el servicio de acceso a Internet en Colombia y ii) precisar los aspectos que limiten o } \\
\text { dificulten la consecución de dicho logro. }\end{array}$ \\
\hline $\mathbf{2 0 1 2}$ & $\begin{array}{l}\text { * Se disuelve a la Comisión Nacional de Televisión (CNTV) y se crea la Agencia } \\
\text { Nacional de Televisión (ANTV) por medio de la Ley 1507 de 2012. }\end{array}$ \\
\hline $\mathbf{2 0 1 3}$ & * En la subasta 4G se asigna espectro a las empresas Avantel y DirecTV. \\
\hline $\mathbf{2 0 1 6}$ & * Se crea el Viceministerio de Economía Digital. \\
$\mathbf{2 0 1 7}$ & * Hoja de Ruta Regulatoria para el Desarrollo de la Economía Digital en Colombia. \\
\hline $\mathbf{2 0 1 8}$ & * Política Nacional de Explotación de Datos. Conpes 3920 del 17 de abril de 2018. \\
\hline
\end{tabular}

Fuente: elaboración propia.

De acuerdo a lo anterior, se indaga si la estructura y dinámica en red de la política pública de regulación del servicio público de las tecnologías de la información y las comunicaciones (TIC) 2009-2018, está orientada por los principios rectores de acceso — universalidad — y equidad como dimensiones de red. 


\section{Referentes teóricos. Análisis de redes sociales}

La operativización del proceso y desarrollo de la investigación se realizó a través del enfoque teórico del análisis de redes sociales (ARS) o Social Network Analysis, sustentado en que la política pública de regulación de TIC se establece a partir de un marco legal — leyes, decretos y resolucionesque cristalizan acuerdos, programas y proyectos que legitiman la praxis de la política pública e involucra una multiplicidad de actores de orden institucional, organizacional, publico-social y público-privado con sus respectivas interacciones, recursos y relaciones (Tabarquino, 2018; González, 2017; Nurul y Verhoest, 2016; González, Nurul y Verhoest, 2015, 12 de junio; Aubin y Verhoest, 2014; Jordana y Levi-Faur, 2005).

De acuerdo a la indagación teórica e instrumental, la aplicación del enfoque del análisis de redes sociales implica la integración de los enfoques metodológicos nominalista y realista (Tabarquino, 2018; 2016; 2015; Machín, 2011; Rama y Luaces, 2007, septiembre), para delimitar e identificar los miembros de la red y analizar de manera adecuada sus relaciones de manera estructural y posicional.

\subsection{Enfoque nominalista. Delimitación de la red}

Se impone un marco conceptual construido para servir a los objetivos analíticos, por lo cual, las fronteras de la red dependen del marco teórico, por lo cual el investigador puede imponer los límites de la estructura investigativa; y se delimita las fronteras de la red en función de los intereses de la investigación, que establece cuáles son los límites de la población de objeto de estudio (Wasserman y Fauts, 2013; Verd y Martí, 1999; Rodríguez, 2005; Cárdenas, 2012a; 2014b; 2016; Aguirre, 2014; Tabarquino, 2015; 2016; 2018; Lozares y Verd, 2015; Kuz, Falco y Giandini, 2016; comunicación personal, Carlos Lozares, 7 de octubre, 2016; Jhoan Miquel Verd, 30 de septiembre, 2016). De la aplicación de este enfoque se deriva la tipología de actores involucrados en una política pública regulatoria de TIC (González, 2017; Tabarquino, 2018; 2016; 2015; González Builes, 2014; González, Nurul, y Verhoest, 2015, 12 de junio; Aubin y Verhoest, 2014; Jordana y Levi-Faur, 2005; Jordana y Sancho, 2004). 
Los principios rectores de política pública de acceso y equidad como dimensiones...

Cuadro 2. Tipología de actores en una política pública de regulación del sector de las TIC.

\begin{tabular}{|l|l|}
\hline \multirow{4}{*}{ Actores reguladores } & $\begin{array}{l}\text { Ministerios } \\
\text { Agencias nacionales de regulación } \\
\text { Comisiones de regulación } \\
\text { Superintendencias } \\
\text { Autoridades nacionales } \\
\text { Departamentos de planeación }\end{array}$ \\
\hline Actores regulados & $\begin{array}{l}\text { Operadores de servicios de TIC: } \\
\text { - Televisión } \\
\text { - Telefonía móvil } \\
\text { - Internet } \\
\text { - Telefonía pública básica conmutada local } \\
\text { - Contenidos }\end{array}$ \\
\hline Actores no regulados & $\begin{array}{l}\text { Organismos de regulación y veeduría internacional } \\
\text { Centros de pensamiento privados y públicos } \\
\text { Asociaciones nacionales de empresas } \\
\text { Asociaciones nacionales de usuarios } \\
\text { ONG y fundaciones } \\
\text { Universidades } \\
\text { Sindicatos } \\
\text { Partidos políticos }\end{array}$ \\
\hline
\end{tabular}

Fuente: elaboración propia.

\subsection{Enfoque realista. Mapeo y relaciones entre actores}

Se acoge la perspectiva de los propios actores de la red para definir sus fronteras, por lo cual la red es tratada como un hecho social, porque es percibida conscientemente como tal por los actores que la integran, es decir, que todas las entidades miembros son conscientes de quién pertenece y quién no; y se opta por delimitar las fronteras de la red en función de la percepción de los integrantes de esta: son los propios integrantes quienes se reconocen como miembros de la red $y$, de esta forma, se define la frontera de la red (Wasserman y Fauts, 2013; Verd y Martí, 1999; Rodríguez, 2005; Cárdenas, 2012b; 2014a; 2016; Aguirre, 2014; Ramilo, 2010; Tabarquino 2015; 2016; 2018; Lozares y Verd, 2015; Kuz, Falco y Giandini, 2016; comunicación personal, María Cármen Ramilo, 15 de junio, 2016). 


\section{Metodología}

La investigación es de tipo exploratorio y empírica, porque proporciona un marco de análisis para la comprensión del fenómeno de la conformación y operación de una política publica en forma de red, buscando llenar los vacíos producidos por la regulación, el mercado y el Estado en el tema específico de TIC. A través de la selección de diferentes unidades de análisis obliga a diferentes tipos de recolección de datos, diferentes focos de análisis y niveles de hallazgos (Patton, 2002, p. 228).

La investigación demanda la utilización de fuentes de información cualitativa —entrevistas, videos, conferencias, conversatorios, revistas, periódicos y estudios sectoriales - y cuantitativa - bases de datos de organismos gremiales, institucionales, público-sociales e internacionales-, y el uso del programa Ucinet 6.0 (Borgatti, Everett y Freeman, 2002) para el análisis de redes sociales, por lo cual el enfoque metodológico es mixto (Eisenhardt, 1989; Patton, 2002, Yin, 2003; Musca, 2006; Langley y Royer, 2006; Tabarquino, 2015; 2016; 2018). A su vez, las fuentes de información se dividen en:

[118] $\square$ Primarias. Entrevistas semiestructuradas y conversatorios a expertos en $\mathrm{TIC}^{1}$ redes de política pública y análisis de redes de sociales; cuestionarios en el tema específico de política pública de TIC en Colombia; c) bases de datos de MinTIC 2009-2018.

Secundarias. Periódicos, artículos, revistas especializadas en TIC, agendas de regulación, leyes de TIC, decretos de la CRC, estudios sectoriales del MinTIC; entrevistas y videoconferencias; informes estadísticos suministrados por el MinTIC, la SIC, la CRC y el DNP; páginas web, revistas, artículos, tesis y proyectos relacionados con el tema de TIC en Colombia, redes de políticas públicas, análisis de redes sociales, regulación y servicios públicos; análisis de los informes de gestión presentados por el MinTIC ante el Congreso de la República de Colombia en 2010-2018; el Plan Nacional de TIC 2008-2019 y Plan Vive Digital 2010-2014, 2014-2018.

\footnotetext{
${ }^{1}$ Las entrevistas y los conversatorios pueden ser corroborados en https://drive.google.com/drive/folde rs/0B0Vro6Z1QP8wRXVURUppSW90Ymc
} 
Los principios rectores de política pública de acceso y equidad como dimensiones...

\section{Resultados}

\subsection{Mapa de actores}

Al consolidar la red política pública de regulación de comunicaciones en Colombia 2009-2018, se obtienen 78 actores, distribuidos en 6 reguladores, 9 regulados y 63 no regulados; la esfera de lo público está representada por 12 actores y la privada por 66; en el ámbito internacional hay 47 actores y en el nacional 31 .

Cuadro 3a. Red de política pública de regulación de comunicaciones en Colombia, 2009-2018. Actores reguladores.

\begin{tabular}{|c|c|c|c|c|}
\hline & Actores reguladores & Rol en el sector & Naturaleza & Contexto \\
\hline 1 & $\begin{array}{l}\text { Ministerio de Tecnologías de la } \\
\text { Información y Comunicaciones }\end{array}$ & Estatal & Público & Nacional \\
\hline 2 & $\begin{array}{l}\text { Comisión de Regulación de } \\
\text { Comunicaciones }\end{array}$ & Estatal & Público & Nacional \\
\hline 3 & Agencia Nacional del Espectro & Estatal & Público & Nacional \\
\hline 4 & $\begin{array}{l}\text { Superintendencia de Industria y } \\
\text { Comercio }\end{array}$ & Estatal & Público & Nacional \\
\hline 5 & Autoridad Nacional de Televisión & Estatal & Público & Nacional \\
\hline 6 & Departamento Nacional de Planeación & Estatal & Público & Nacional \\
\hline
\end{tabular}

Fuente: elaboración propia.

Cuadro 3b. Red de política pública de regulación de comunicaciones en Colombia, 2009-2018. Actores regulados.

\begin{tabular}{|c|c|c|c|c|}
\hline & Actores regulados & Rol en el sector & Naturaleza & Contexto \\
\hline 7 & Claro (Comcel, Telmex, Claro TV) & Operador & Privado & Internacional \\
\hline 8 & $\begin{array}{l}\text { Telefónica Movistar (Colombia } \\
\text { Telecomunicaciones, Movistar Video) }\end{array}$ & Operador & Privado & Internacional \\
\hline 9 & $\begin{array}{l}\text { Tigo-Une (Tigo, Millicom, UNE-EPM, } \\
\text { Edatel, Orbitel) }\end{array}$ & Operador & Privado & Internacional \\
\hline 10 & Uff Móvil & Operador & Privado & Internacional \\
\hline 11 & Virgin Mobile & Operador & Privado & Internacional \\
\hline 12 & Movil Éxito & Operador & Privado & Nacional \\
\hline
\end{tabular}


Cuadro 3b. (Continuación)

\begin{tabular}{|l|l|l|l|l|}
\hline 13 & Avantel & Operador & Privado & Internacional \\
\hline 14 & DirecTV & Operador & Privado & Internacional \\
\hline 15 & ETB & Operador & Publico & Nacional \\
\hline
\end{tabular}

Fuente: elaboración propia.

Cuadro 3c. Red de política pública de regulación de comunicaciones en Colombia, 2009-2018. Actores nacionales no regulados.

\begin{tabular}{|l|l|l|l|l|}
\hline \multicolumn{2}{|c|}{ Actores no regulados } & Rol en el sector & Naturaleza & Contexto \\
\hline 16 & $\begin{array}{l}\text { Asociación de la Empresa Móvil de } \\
\text { Colombia (Asomovil) }\end{array}$ & $\begin{array}{l}\text { Organización } \\
\text { gremial }\end{array}$ & Privado & Nacional \\
\hline 17 & $\begin{array}{l}\text { Cámara Colombiana de Informática y } \\
\text { Telecomunicaciones (CCIT) }\end{array}$ & $\begin{array}{l}\text { Organización } \\
\text { gremial }\end{array}$ & Privado & Nacional \\
\hline 18 & $\begin{array}{l}\text { Asociación Nacional de Empresas de } \\
\text { Servicios Públicos y Comunicaciones } \\
\text { (Andesco) }\end{array}$ & $\begin{array}{l}\text { Organización } \\
\text { gremial }\end{array}$ & Privado & Nacional \\
\hline 19 & $\begin{array}{l}\text { Cámara Colombiana de Comercio } \\
\text { Electrónico (CCCE) }\end{array}$ & $\begin{array}{l}\text { Organización } \\
\text { gremial }\end{array}$ & Privado & Nacional \\
\hline 20 & $\begin{array}{l}\text { Federación Colombiana de la Industria } \\
\text { de Software y TI (Fedesoft) }\end{array}$ & $\begin{array}{l}\text { Organización } \\
\text { gremial }\end{array}$ & Privado & Nacional \\
\hline 21 & $\begin{array}{l}\text { Centro de Investigación de las } \\
\text { Telecomunicaciones (Cintel) }\end{array}$ & $\begin{array}{l}\text { Organización } \\
\text { consultora }\end{array}$ & Privado & Nacional \\
\hline 22 & $\begin{array}{l}\text { Fundación para la Educación Superior y } \\
\text { el Desarrollo (Fedesarrollo) }\end{array}$ & $\begin{array}{l}\text { Organización } \\
\text { consultora }\end{array}$ & Privado & Nacional \\
\hline 23 & $\begin{array}{l}\text { Asociación Colombiana de Ingenieros } \\
\text { (Aciem) }\end{array}$ & $\begin{array}{l}\text { Organización } \\
\text { consultora }\end{array}$ & Privado & Nacional \\
\hline 24 & Corporación Colombia Digital & $\begin{array}{l}\text { Organización } \\
\text { consultora }\end{array}$ & Privado & Nacional \\
\hline 25 & $\begin{array}{l}\text { Confederación de Comités y Vocales de } \\
\text { Control (Confevocoltics) }\end{array}$ & $\begin{array}{l}\text { Organización } \\
\text { social }\end{array}$ & Privado \\
\hline 26 & $\begin{array}{l}\text { Asociación Colombiana de Usuarios de } \\
\text { Internet (ACUI) }\end{array}$ & $\begin{array}{l}\text { Organización } \\
\text { social }\end{array}$ & Privado \\
Social & Fundación Karisma & Nniversidad & Privado & Nacional \\
\hline 28 & Universidad de los Andes & Universidad & Privado & Nacional \\
\hline 29 & Universidad del Externado & Nado & Nacional \\
\hline
\end{tabular}


Los principios rectores de política pública de acceso y equidad como dimensiones...

Cuadro 3c. (Continuación)

\begin{tabular}{|l|l|l|l|l|}
\hline 30 & Universidad Javeriana & Universidad & Privado & Nacional \\
\hline 31 & Contraloría General de la Nación & $\begin{array}{l}\text { Órgano de } \\
\text { control }\end{array}$ & Publico & Nacional \\
\hline 32 & Procuraduría General de la Nación & $\begin{array}{l}\text { Órgano de } \\
\text { control }\end{array}$ & Publico & Nacional \\
\hline 33 & Congreso de la Republica & $\begin{array}{l}\text { Órgano de } \\
\text { control }\end{array}$ & Publico & Nacional \\
\hline 34 & Partido Cambio Radical & Partido político & Publico & Nacional \\
\hline 35 & Partido Liberal & Partido político & Publico & Nacional \\
\hline 36 & Grupo Éxito & $\begin{array}{l}\text { Grupo } \\
\text { empresarial }\end{array}$ & Privado & Nacional \\
\hline 37 & Grupo EPM & $\begin{array}{l}\text { Grupo } \\
\text { empresarial }\end{array}$ & Privado & Nacional \\
\hline 38 & Grupo Bancolombia & $\begin{array}{l}\text { Grupo } \\
\text { empresarial }\end{array}$ & Privado & Nacional \\
\hline
\end{tabular}

Fuente: elaboración propia.

Cuadro 3d. Red de política pública de regulación de comunicaciones en Colombia, 2009-2018. Actores internacionales no regulados.

\begin{tabular}{|c|c|c|c|c|}
\hline \multicolumn{5}{|c|}{ Actores no regulados } \\
\hline & Actores Internacionales & Rol en el sector & Naturaleza & Contexto \\
\hline 39 & Grupo Vigin Mobile & Grupo empresarial & Privado & Internacional \\
\hline 40 & Grupo Salinas & Grupo empresarial & Privado & Internacional \\
\hline 41 & $\begin{array}{l}\text { Unión Internacional de } \\
\text { Telecomunicaciones (UTI) }\end{array}$ & $\begin{array}{l}\text { Organización especializada } \\
\text { en telecomunicaciones }\end{array}$ & Privado & Internacional \\
\hline 42 & $\begin{array}{l}\text { International } \\
\text { Telecommunications Satellite } \\
\text { Organization (ITSO) }\end{array}$ & $\begin{array}{l}\text { Organización especializada } \\
\text { en telecomunicaciones }\end{array}$ & Privado & Internacional \\
\hline 43 & $\begin{array}{l}\text { International Mobile Satellite } \\
\text { Organization (IMSO) }\end{array}$ & $\begin{array}{l}\text { Organización especializada } \\
\text { en telecomunicaciones }\end{array}$ & Privado & Internacional \\
\hline 44 & $\begin{array}{l}\text { Comité Andino de Autoridades } \\
\text { de Telecomunicaciones } \\
\text { (CAATEL) }\end{array}$ & $\begin{array}{l}\text { Organización especializada } \\
\text { en telecomunicaciones }\end{array}$ & Privado & Internacional \\
\hline 45 & $\begin{array}{l}\text { Banco de Desarrollo de } \\
\text { América Latina (CAF) }\end{array}$ & Organización financiera & Privado & Internacional \\
\hline 46 & $\begin{array}{l}\text { Banco Interamericano de } \\
\text { Desarrollo (BID) }\end{array}$ & Organización financiera & Privado & Internacional \\
\hline 47 & Banco Mundial (BM) & Organización financiera & Privado & Internacional \\
\hline 48 & $\begin{array}{l}\text { Comisión Interamericana de } \\
\text { Telecomunicaciones (Citel) }\end{array}$ & Organización consultora & Privado & Internacional \\
\hline
\end{tabular}


Cuadro 3d. (Continuación)

\begin{tabular}{|c|c|c|c|c|}
\hline 49 & Universal Postal Union (UPU) & Organización consultora & Privado & Internacional \\
\hline 50 & $\begin{array}{l}\text { Unión Postal de las Américas, } \\
\text { España y Portugal (UPAEP) }\end{array}$ & Organización consultora & Privado & Internacional \\
\hline 51 & $\begin{array}{l}\text { Organización Marítima } \\
\text { Internacional }(\mathrm{OMI})\end{array}$ & Organización consultora & Privado & Internacional \\
\hline 52 & $\begin{array}{l}\text { Organización de Aviación } \\
\text { Civil Internacional }(\mathrm{OACl})\end{array}$ & Organización consultora & Privado & Internacional \\
\hline 53 & $\begin{array}{l}\text { Organización Mundial del } \\
\text { Comercio (OMC) }\end{array}$ & Organización consultora & Privado & Internacional \\
\hline 54 & $\begin{array}{l}\text { Organización para la } \\
\text { Cooperación y el Desarrollo } \\
\text { Económicos (OCDE) } \\
\end{array}$ & Organización consultora & Privado & Internacional \\
\hline 55 & $\begin{array}{l}\text { Comisión Económica para } \\
\text { América Latina y el Caribe } \\
\text { (Cepal) }\end{array}$ & Organización consultora & Privado & Internacional \\
\hline 56 & \begin{tabular}{|l|} 
Foro Latinoamericano \\
de Entes Reguladores de \\
Telecomunicaciones (Regulatel) \\
\end{tabular} & Organización consultora & Privado & Internacional \\
\hline 57 & $\begin{array}{l}\text { Organización de las Naciones } \\
\text { Unidas para la Educación, la } \\
\text { Ciencia y la Cultura (Unesco) }\end{array}$ & Organización consultora & Privado & Internacional \\
\hline 58 & $\begin{array}{l}\text { Organización de los Estados } \\
\text { Americanos (OEA) }\end{array}$ & Organización consultora & Privado & Internacional \\
\hline 59 & $\begin{array}{l}\text { Telecomunicaciones en } \\
\text { América Latina (Asiet) } \\
\end{array}$ & Organización consultora & Privado & Internacional \\
\hline 60 & $\begin{array}{l}\text { Facebook (You tube, WhatsApp, } \\
\text { Instagram, FB Messenger) }\end{array}$ & Servicio OTT & Privado & Internacional \\
\hline 61 & Twitter & Servicio OTT & Privado & Internacional \\
\hline 62 & Google & Servicio OTT & Privado & Internacional \\
\hline 63 & Netflix & Servicio OTT & Privado & Internacional \\
\hline 64 & Microsoft & $\begin{array}{l}\text { Empresa de fabricación e } \\
\text { innovación TIC }\end{array}$ & Privado & Internacional \\
\hline 65 & Sony & $\begin{array}{l}\text { Empresa de fabricación e } \\
\text { innovación TIC }\end{array}$ & Privado & Internacional \\
\hline 66 & Apple & $\begin{array}{l}\text { Empresa de fabricación e } \\
\text { innovación TIC }\end{array}$ & Privado & Internacional \\
\hline 67 & IBM & $\begin{array}{l}\text { Empresa de fabricación e } \\
\text { innovación TIC }\end{array}$ & Privado & Internacional \\
\hline 68 & Huawei & $\begin{array}{l}\text { Empresa de fabricación e } \\
\text { innovación TIC }\end{array}$ & Privado & Internacional \\
\hline 69 & Ericsson & $\begin{array}{l}\text { Empresa de fabricación e } \\
\text { innovación TIC }\end{array}$ & Privado & Internacional \\
\hline 70 & ATC & $\begin{array}{l}\text { Empresa de fabricación e } \\
\text { innovación TIC }\end{array}$ & Privado & Internacional \\
\hline
\end{tabular}


Los principios rectores de política pública de acceso y equidad como dimensiones...

Cuadro 3d. (Continuación)

\begin{tabular}{|l|l|l|l|l|}
\hline 71 & Azteca Comunicaciones & $\begin{array}{l}\text { Empresa licitadora y } \\
\text { ganadora de proyectos } \\
\text { infraestructura de TIC }\end{array}$ & Privado & Internacional \\
\hline 72 & Energía Integral Andina & $\begin{array}{l}\text { Empresa licitadora y } \\
\text { ganadora de proyectos } \\
\text { infraestructura de TIC }\end{array}$ & Privado & Internacional \\
\hline 73 & Total Play & $\begin{array}{l}\text { Empresa licitadora y } \\
\text { ganadora de proyectos } \\
\text { infraestructura de TIC }\end{array}$ & Privado & Internacional \\
\hline 74 & Anditel & $\begin{array}{l}\text { Empresa licitadora y } \\
\text { ganadora proyectos } \\
\text { infraestructura de TIC }\end{array}$ & Privado & Internacional \\
\hline 75 & Grupos Hispasat & $\begin{array}{l}\text { Empresa licitadora y } \\
\text { ganadora proyectos } \\
\text { infraestructura de TIC }\end{array}$ & Privado & Internacional \\
\hline 76 & NEC de Colombia & $\begin{array}{l}\text { Empresa licitadora y } \\
\text { ganadora proyectos } \\
\text { infraestructura de TIC }\end{array}$ & Privado & Internacional \\
\hline 77 & Cisco & $\begin{array}{l}\text { Empresa licitadora y } \\
\text { ganadora proyectos } \\
\text { infraestructura de TIC }\end{array}$ & Privado & Internacional \\
\hline 78 & BT & $\begin{array}{l}\text { Empresa licitadora y } \\
\text { ganadora proyectos } \\
\text { infraestructura de TIC }\end{array}$ & Privado & Internacional \\
\hline
\end{tabular}

Fuente: elaboración propia.

Al agrupar estos actores en las categorías del marco de análisis, la participación dentro de la red equivale a $8 \%$ reguladores, 12\% regulados y $80 \%$ no regulados. La mayoría son de naturaleza privada (85\%) y en menor grado público (15\%); existen más actores internacionales (60\%) que nacionales (40\%).

De acuerdo a la configuración del rol en el sector, 8\% son estales, 12\% son operadores, $8 \%$ son gremios, $19 \%$ son consultoras, $6 \%$ grupos empresariales, $4 \%$ organizaciones sociales, 4\% organizaciones financieras, 5\% organizaciones especializadas en telecomunicaciones, 4\% universidades, 3\% partidos políticos, 4\% órganos de control, 5\% servicios OTT, 2 9\% empresas de fabricación e

${ }^{2}$ Los servicios OTT son relevantes en el análisis de la estructura en red, porque compiten de manera
directa con los servicios ofrecidos tradicionalmente por las compañías de telecomunicaciones - voz,
mensajería y TV paga - sin una regulación establecida; y porque son controlados por compañías 
innovación de TIC y 10\% empresas licitadoras y ganadoras de proyectos de infraestructura.

Tabla 1. Cuantificación de la red de política pública de regulación de comunicaciones en Colombia, 2009-2018.

\begin{tabular}{|c|c|c|c|c|c|c|c|}
\hline Actores & Rol & Público & Privado & Nacional & Internacional & Total & Porcentaje \\
\hline Reguladores & Estatales & 6 & 0 & 6 & 0 & 6 & $8 \%$ \\
\hline Regulados & $\begin{array}{l}\text { Principales } \\
\text { operadores }\end{array}$ & 1 & 8 & 2 & 7 & 9 & $12 \%$ \\
\hline \multirow{12}{*}{$\begin{array}{l}\text { No } \\
\text { regulados }\end{array}$} & Gremial & 0 & 6 & 5 & 11 & 6 & $8 \%$ \\
\hline & Consultoras & 0 & 15 & 4 & 11 & 15 & $19 \%$ \\
\hline & $\begin{array}{l}\text { Grupos } \\
\text { empresariales }\end{array}$ & 0 & 5 & 3 & 2 & 5 & $6 \%$ \\
\hline & Sociales & 0 & 3 & 3 & 0 & 3 & $4 \%$ \\
\hline & Financieras & 0 & 3 & 0 & 3 & 3 & $4 \%$ \\
\hline & $\begin{array}{l}\text { Especializadas } \\
\text { en TIC }\end{array}$ & 0 & 4 & 0 & 4 & 4 & $5 \%$ \\
\hline & Universidades & 0 & 3 & 3 & 0 & 3 & $4 \%$ \\
\hline & $\begin{array}{l}\text { Partido } \\
\text { político } \\
\end{array}$ & 2 & 0 & 2 & 0 & 2 & $3 \%$ \\
\hline & $\begin{array}{l}\begin{array}{l}\text { Órgano de } \\
\text { control }\end{array} \\
\end{array}$ & 3 & 0 & 3 & 0 & 3 & $4 \%$ \\
\hline & OTT & 0 & 4 & 0 & 4 & 4 & $5 \%$ \\
\hline & $\begin{array}{l}\text { Fabricación } \\
\text { e innovación } \\
\text { TIC }\end{array}$ & 0 & 7 & 0 & 7 & 7 & $9 \%$ \\
\hline & \begin{tabular}{|l|} 
Licitadora \\
y ganadora \\
proyectos \\
infraestructura \\
TIC
\end{tabular} & 0 & 8 & 0 & 8 & 8 & $10 \%$ \\
\hline \multicolumn{2}{|l|}{ Total } & 12 & 66 & 31 & 47 & 78 & $100 \%$ \\
\hline \multicolumn{2}{|l|}{\begin{tabular}{|l|} 
Porcentaje \\
\end{tabular}} & $15 \%$ & $85 \%$ & $40 \%$ & $60 \%$ & $100 \%$ & \\
\hline
\end{tabular}

Fuente: elaboración propia.

de alcance global y solidez financiera - Google, Facebook, Microsoft-, fabricantes de productos electrónicos de consumo - Apple, RIM - y empresas de medios de comunicación — Sony Music, Universal-(Lopasso, 2011, p. 2). 
Los principios rectores de política pública de acceso y equidad como dimensiones...

\subsection{Matriz y visualización de la red}

La matriz de actores de la red de política pública de regulación de las comunicaciones en Colombia 2009-2018, se organiza en 78 filas y 78 columnas, donde la existencia de relación equivale a 1 y la existencia de no relación equivale a 0 . La matriz es de orden simétrico y se inserta en el programa Ucinet 6.0 (Borgatti, Everett y Freeman, 2002) para su posterior visualización.

Acceso y equidad se configuran como dimensiones de red de política pública, sustentado en que son fines y no medios de la implementación de diferentes programas y proyectos que buscan consolidar la sociedad de la información y del conocimiento en Colombia, y el desarrollo de una sociedad en cuanto a un pensamiento con valor agregado que se deriva de los procesos de la asimilación de las TIC como herramientas para la solución de problemas. Esto se da por la consolidación de una sociedad en red, que construye valores y dinámicas alrededor de la gobernabilidad y la gobernanza de Internet, creando redes de información y nuevas formas de pensamiento complejas en tiempo real.

Cuadro 4. Acceso y Equidad como dimensiones

de red de política pública para el sector de las TIC.

\begin{tabular}{|l|l|}
\hline Dimensión & \multicolumn{1}{c|}{ Definición } \\
\hline \multirow{5}{*}{ Acceso } & $\begin{array}{l}\text { Pertenecen asociaciones o gremios del sector TIC que participan activamente } \\
\text { en procesos estatales y privados en relación con el esquema regulatorio del } \\
\text { sector. }\end{array}$ \\
\cline { 2 - 3 } & $\begin{array}{l}\text { Realiza actividades en la generación, consolidación y apropiación de } \\
\text { información y el conocimiento —-congresos, mesas temáticas y seminarios-- } \\
\text { integrando o convocando a otras organizaciones. }\end{array}$ \\
\cline { 2 - 3 } & $\begin{array}{l}\text { Lidera o participa en proyectos de TIC con otras organizaciones en } \\
\text { conectividad, innovación, infraestructura, apropiación de tecnología y } \\
\text { creación de contenidos. }\end{array}$ \\
\cline { 2 - 3 } & $\begin{array}{l}\text { Lidera o participa en proyectos de masificación y apropiación de TIC - } \\
\text { Alfabetización digital, gestión de la información, nuevos contenidos digitales, } \\
\text { economía digital, revistas especializadas, estudios del sector, congresos } \\
\text { especializados- que involucran a organizaciones del sector. }\end{array}$ \\
\hline
\end{tabular}


Cuadro 4. (Continuación)

\begin{tabular}{|c|c|}
\hline Acceso & $\begin{array}{l}\text { Destina o gestiona recursos para financiar proyectos de conectividad, } \\
\text { innovación, infraestructura, apropiación de tecnología y creación de } \\
\text { contenidos con organizaciones del sector. }\end{array}$ \\
\hline \multirow{12}{*}{ Equidad } & Lidera o participa en proyectos de inclusión social con herramientas de TIC. \\
\hline & Lidera o participa en proyectos de discapacidad visual y sordos para el uso. \\
\hline & Lidera o participa en proyectos de teletrabajo. \\
\hline & Lidera o participa en proyectos de telesalud. \\
\hline & $\begin{array}{l}\text { Lidera o participa en proyectos de competencias ciudadanas e inclusión social } \\
\text { a partir de la aplicación de las TIC como herramientas. }\end{array}$ \\
\hline & $\begin{array}{l}\text { Lidera o participa en proyectos de producción de contenidos educativos } \\
\text { digitales. }\end{array}$ \\
\hline & $\begin{array}{l}\text { Lidera o participa en proyectos de asistencia a comunidades locales en } \\
\text { riesgo de desplazamiento, aplicando la apropiación de TIC y la gestión de la } \\
\text { información y el conocimiento. }\end{array}$ \\
\hline & $\begin{array}{l}\text { Lidera o participa en programas de uso responsable de Internet -En TIC } \\
\text { Confío-. }\end{array}$ \\
\hline & $\begin{array}{l}\text { Lidera o participa en programas de emprendedores que convierten sus ideas } \\
\text { en negocios en el sector de las TIC - Programa Apps-. }\end{array}$ \\
\hline & $\begin{array}{l}\text { Destina recursos en proyectos de conectividad, innovación, infraestructura, } \\
\text { apropiación de tecnología y creación de contenidos de manera directa, } \\
\text { integrando otras organizaciones. }\end{array}$ \\
\hline & $\begin{array}{l}\text { Diseña e implementa proyectos, programas y actividades de responsabilidad } \\
\text { social corporativa. }\end{array}$ \\
\hline & Participa en proyectos sociales e inversiones en TIC. \\
\hline
\end{tabular}

Fuente: elaboración propia.

El anterior cuadro se basa en los hechos de la transacción de recursos, la definición de las dimensiones teóricas de las relaciones entre actores, las propiedades estructurales y posicionales de una red, y la importancia del análisis de la relación actor-estructura y del juego político en el tema del poder (Emerson, 1962; Scharpf, 1997; Latour, 2005; Garrido, 2001; Jordana, 2009; Grau, Íñiguez y Subirats, 2010; Serna, 2012; Zurbriggen, 2004; Cárdenas 2016; 2014a; 2012a; comunicación personal, Laura Chaqués, 10 de octubre, 2016; Jacint Jordana, 20 de julio, 2016; Cristina Zurbriggen, 25 de mayo, 2016). 
Gráfica 1. Acceso como dimensión de red de política pública de regulación de las TIC en Colombia, 2009-2018.

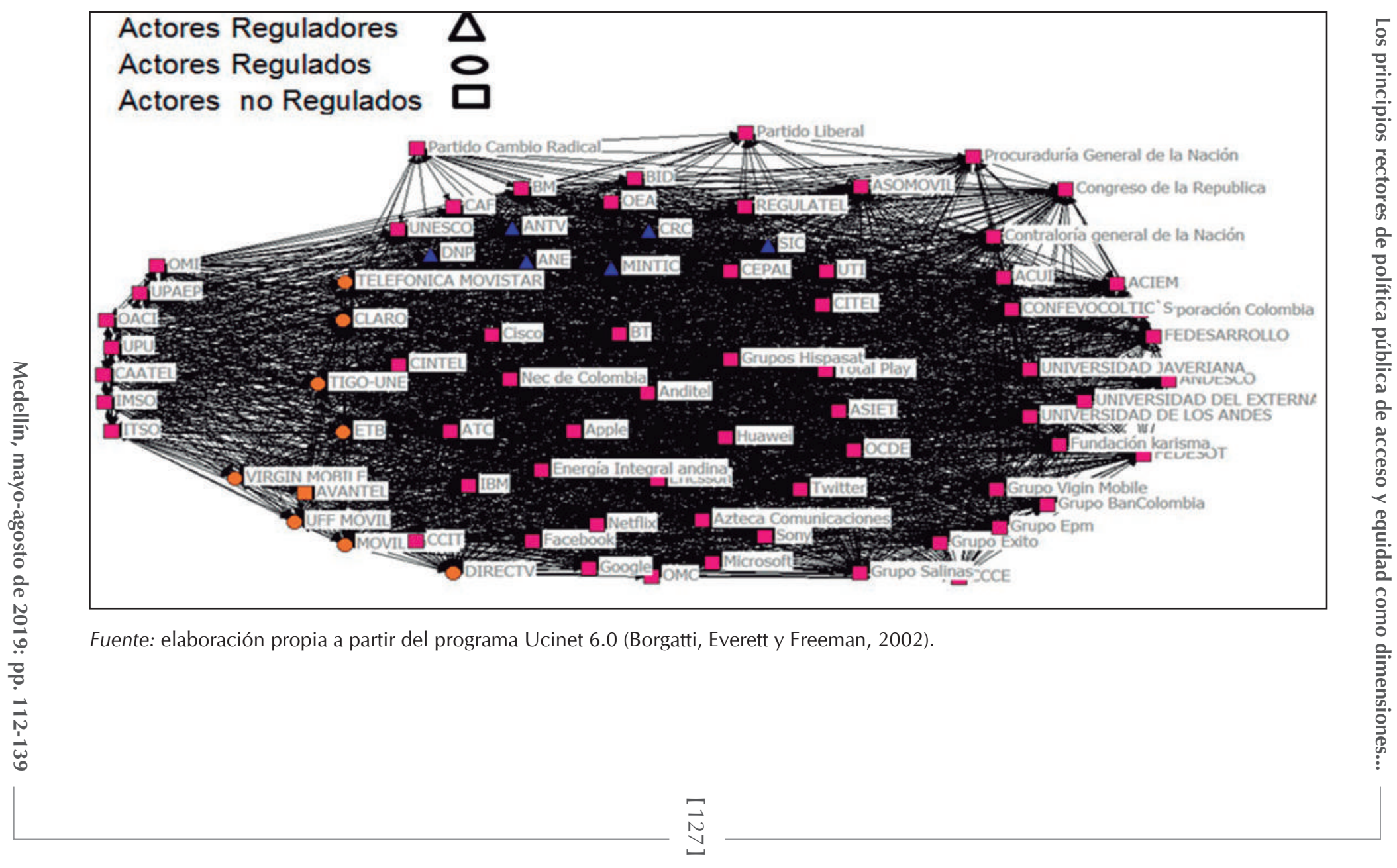


Gráfica 2. Equidad como dimensión de red de política pública de regulación de las TIC en Colombia, 2009-2018.

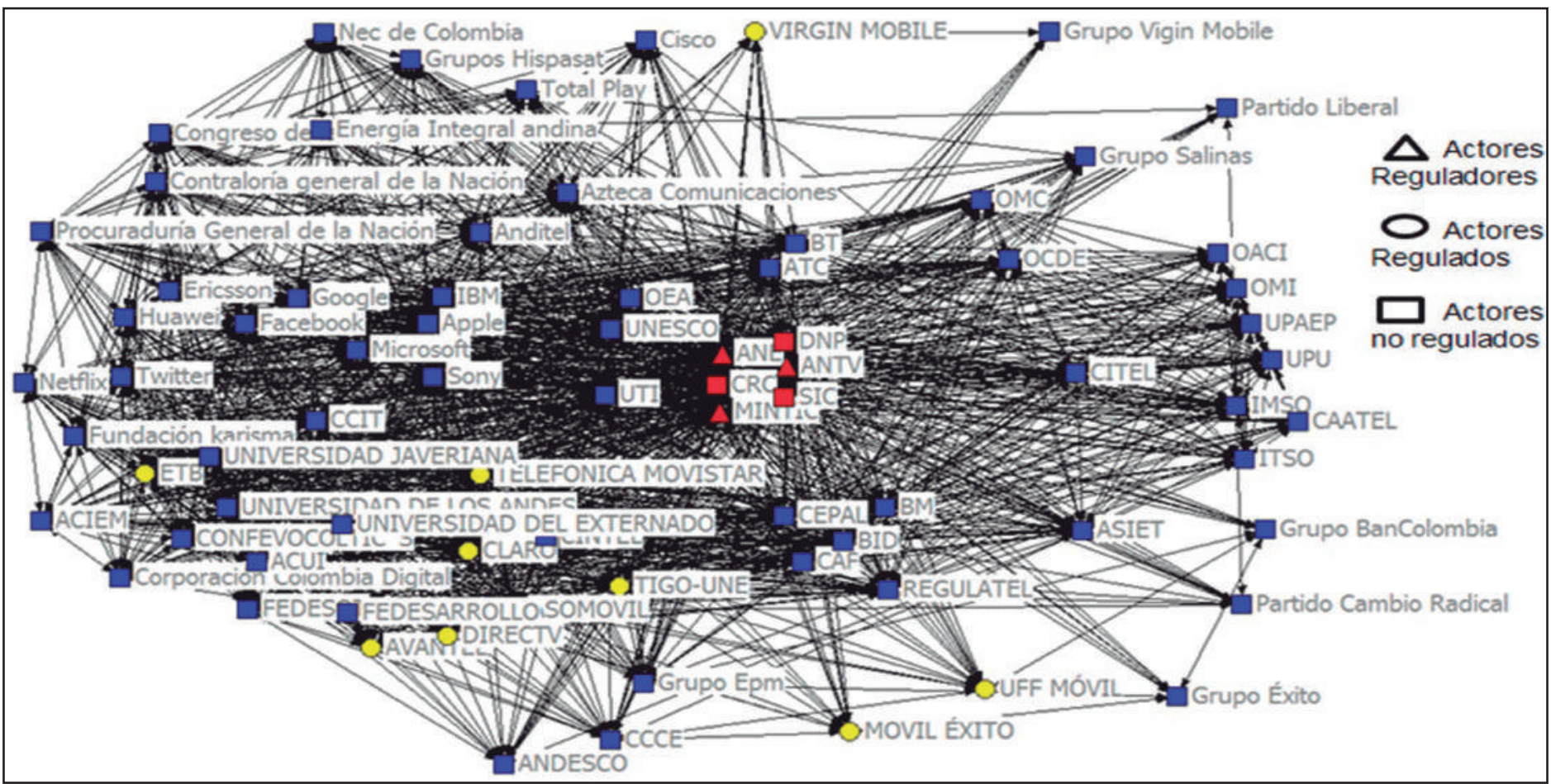

Fuente: elaboración propia a partir del programa Ucinet 6.0 (Borgatti, Everett y Freeman, 2002). 
Los principios rectores de política pública de acceso y equidad como dimensiones...

\section{Discusión}

\subsection{Análisis estructural}

Los resultados de la tabla 2 permiten comparar los dos principios rectores de política pública. El acceso evidencia una densidad (89\%) que da cuenta del alto grado en que sus miembros están vinculados con otros, es decir, alta conectividad entre sus actores; por el contario la equidad evidencia una densidad (53\%) que da cuenta del aceptable grado en que sus miembros están vinculados con otros, es decir, regularidad de conectividad entre sus actores.

Tabla 2. Indicadores estructurales de acceso y equidad como dimensiones de red de política pública de regulación de las TIC en Colombia, 2009-2018.

\begin{tabular}{|c|c|c|c|}
\hline \multicolumn{2}{|c|}{ Indicadores estructurales de la red } & Acceso & Equidad \\
\hline Nodos o actores & $\begin{array}{l}\text { Representa el número de personas, grupos u } \\
\text { organizaciones de la red (nxn). }\end{array}$ & 78 & \\
\hline $\begin{array}{l}\text { Las relaciones posibles de } \\
\text { la red }\end{array}$ & $\begin{array}{l}\mathrm{Rp}=\mathrm{nx}(\mathrm{n}-1) . \text { Número total de nodos por el } \\
\text { número total de nodos menos uno. }\end{array}$ & 6006 & \\
\hline Relaciones existentes & Se suma el total de filas o de columnas. & 5364 & 3176 \\
\hline Densidad de la red & $\begin{array}{l}\mathrm{D}=(\mathrm{Re} / \mathrm{Rp}) \times 100 \text {. Número de relaciones } \\
\text { existentes dividido entre las posibles y } \\
\text { multiplicado por } 100 \text {. La proporción de } \\
\text { vínculos existentes en un grupo sobre el } \\
\text { total de vínculos posibles, como medida } \\
\text { básica de la estructura de la red, da cuenta } \\
\text { del grado en que sus miembros están } \\
\text { vinculados con otros. Permite conocer la alta } \\
\text { o baja conectividad entre los actores. }\end{array}$ & $89 \%$ & $53 \%$ \\
\hline $\begin{array}{l}\text { Distancia geodésica } \\
\text { o diámetro de la red } \\
\text { construida }\end{array}$ & $\begin{array}{l}\text { Promedio de nodos que debe cruzarse para } \\
\text { alcanzar a todos los nodos, número de } \\
\text { relaciones en el camino más corto posible } \\
\text { de un actor a otro o camino más corto entre } \\
\text { dos nodos. }\end{array}$ & 1.1 & 1.5 \\
\hline $\begin{array}{l}\text { Distance-Based Cohesion } \\
\text { (Compactness) o cohesión } \\
\text { basada en la distancia }\end{array}$ & $\begin{array}{l}\text { Mide el grado de interconexión entre } \\
\text { actores. Probabilidad de la unión completa } \\
\text { de los actores. }\end{array}$ & $94 \%$ & $76 \%$ \\
\hline $\begin{array}{l}\text { La media de todas las } \\
\text { relaciones }\end{array}$ & $\begin{array}{l}\text { Indica el promedio de conexiones que tiene } \\
\text { los actores en la red. }\end{array}$ & 68.7 & 40.7 \\
\hline
\end{tabular}


Tabla 2. (Continuación)

\begin{tabular}{|l|l|c|c|}
\hline $\begin{array}{l}\text { Valor mínimo y valor } \\
\text { máximo }\end{array}$ & Menor y mayor cantidad de lazos en la red. & $22-77$ & $7-77$ \\
\hline La desviación estándar & Indica la dispersión entre los actores. & 10.2 & 17.6 \\
\hline $\begin{array}{l}\text { Network Centralization o } \\
\text { índice de centralización }\end{array}$ & $\begin{array}{l}\text { Mide si la red se comporta como una } \\
\text { red estrella, es decir, si existe un solo } \\
\text { actor central en la red o hay un actor que } \\
\text { desempeña un papel central que controla a } \\
\text { toda la red. } \\
\text { IC }=100 \% \text { red estrella } \\
\text { IC }=0 \% \text { red horizontal }\end{array}$ & $10,9 \%$ & $48,3 \%$ \\
\hline
\end{tabular}

Fuente: elaboración propia.

En relación con la distancia geodésica de las dos redes, es menor el acceso (1.1) respecto a la equidad (1.5), lo cual implica que la equidad tiene un promedio más alto de nodos que debe cruzarse para alcanzar a todos los nodos o un número más alto de relaciones en el camino más corto posible de un actor a otro.

Aplicando el indicador de la cohesión basada en la distancia, la [130 ] tendencia de la red de acceso (94\%) entre las relaciones de actores es más simétrica que la de equidad (76\%) como dimensión de red, pero ambas redes tienen alta probabilidad de la unión completa de los actores.

La media de las relaciones para acceso (68.7) y para equidad (40.7) se igualan en relación al máximo de lazos en la red para ambas dimensiones (77), pero difieren en el valor mínimo de acceso (22) y de equidad (7).

El índice de centralización permite evidenciar que la red de acceso $(10,9 \%)$ es más horizontal que la red de equidad (48,3\%). Por otro lado, la red de equidad se inclina a una red estrella y la red de acceso no, pero ambas redes, a pesar de su diferencia, evidencian heterogeneidad de actores en la red y que no hay un actor que desempeñe un papel central que controle toda la red.

\subsection{Análisis posicional}

El análisis posicional de acceso y equidad establece los siguientes indicadores, los cuales, se describen relacionando actores reguladores, actores regulados y actores no regulados, con el fin de establecer la dinámica de las subredes: 
Cuadro 5. Indicadores posicionales de acceso y equidad como dimensiones de red de política pública de regulación de las TIC en Colombia, 2009-2018.

\begin{tabular}{|c|c|c|c|}
\hline \multicolumn{2}{|c|}{ Indicadores posicionales de la red } & Acceso & Equidad \\
\hline $\begin{array}{l}\text { Rango-grado } \\
\text { nodal (degree). } \\
\text { Centralidad } \\
\text { grado }\end{array}$ & $\begin{array}{l}\text { Evidencia los actores } \\
\text { centrales en la red. } \\
\text { Evidencia el número } \\
\text { de lazos directos de } \\
\text { un actor o nodo, es } \\
\text { decir, con cuántos otros } \\
\text { nodos se encuentra } \\
\text { directamente conectado. }\end{array}$ & $\begin{aligned} * & \text { MinTIC, CRC, SIC, } \\
& \text { DNP, ANE y ANTV } \\
& \text { (77) con } 100 \% \\
* & \text { UTI, Cepal y OEA } \\
& \text { (77) con } 100 \% \\
* & \text { Telefónica- } \\
& \text { Movistar, Claro, } \\
& \text { Tigo-Une (74) con } \\
& 96 \%\end{aligned}$ & $\begin{aligned} * & \text { MinTIC, CRC, SIC, } \\
& \text { DNP, ANE y ANTV } \\
& (77) \text { con } 100 \% \\
* & \text { UTI (66) con } 85 \% \\
* & \text { Telefónica-Movistar, } \\
& \text { Tigo-Une (48) con } \\
& 62 \% \\
* & \text { Claro (47) con } 61 \%\end{aligned}$ \\
\hline $\begin{array}{l}\text { Grado de } \\
\text { intermediación } \\
\text { (betweenness). } \\
\text { Centralidad de } \\
\text { intermediación }\end{array}$ & $\begin{array}{l}\text { Proporción de veces que } \\
\text { un actor está en la ruta } \\
\text { entre distintos pares de } \\
\text { actores. } \\
\text { Indica la frecuencia con } \\
\text { que aparece un nodo } \\
\text { en el tramo más corto } \\
\text { (geodésico) que conecta } \\
\text { a otros dos. Es decir, } \\
\text { muestra cuando un actor } \\
\text { es intermediario entre } \\
\text { otros dos actores del } \\
\text { mismo grupo que no } \\
\text { se conocen entre sí, lo } \\
\text { que se denomina «actor } \\
\text { puente». }\end{array}$ & $\begin{array}{l}\text { * MinTIC, CRC, SIC, } \\
\text { DNP, ANE y ANTV } \\
\text { (9.5) con 0,3\% } \\
\text { * UTI, Cepal y OEA } \\
\text { (9.5) con 0,3\% } \\
\text { * Asomovil (7.5) con } \\
\text { 0,25\% } \\
\text { * Telefónica- } \\
\text { Movistar, Claro, } \\
\text { Tigo-Une (5.5) con } \\
\text { 0,19\% }\end{array}$ & $\begin{array}{l}* \text { MinTIC, CRC, SIC, } \\
\text { DNP, ANE y ANTV } \\
\text { (119.6) con } 4 \% \\
* \text { UTI (50.7) con 1,7\% } \\
* \text { Tigo-Une (15) con } \\
\text { 0,5\% } \\
* \text { Telefónica-Movistar } \\
\text { (14) con 0,4\% } \\
\text { * Claro (11.4) con } \\
\text { 0,39\% }\end{array}$ \\
\hline $\begin{array}{l}\text { Grado de } \\
\text { cercanía } \\
\text { (closenness). } \\
\text { Centralidad de } \\
\text { cercanía }\end{array}$ & $\begin{array}{l}\text { Este indicador se calcula } \\
\text { si la matriz es simétrica, } \\
\text { indica la cercanía de un } \\
\text { nodo respecto del resto } \\
\text { de la red. Representa la } \\
\text { capacidad que tiene un } \\
\text { nodo de alcanzar a los } \\
\text { demás. }\end{array}$ & $\begin{array}{l}\text { * MinTic, CRC, SIC, } \\
\text { DNP, ANE y ANTV } \\
\text { Cercanía }=100 \\
\text { Lejanía }=77 \\
\text { * } \\
\text { UTI, Cepal y OEA } \\
\text { Cercanía }=100 \\
\text { Lejanía }=77 \\
\text { * Telefónica- } \\
\text { Movistar, Claro, } \\
\text { Tigo-Une } \\
\text { Cercanía }=96.2 \\
\text { Lejanía }=80\end{array}$ & $\begin{array}{l}\text { * MinTic, CRC, SIC, } \\
\text { DNP, ANE y ANTV } \\
\text { Cercanía }=100 \\
\text { Lejanía }=77 \\
\text { * } \\
\text { UTI } \\
\text { Cercanía }=87 \\
\text { Lejanía }=88 \\
\text { * Telefónica-Movistar, } \\
\text { Tigo-Une } \\
\text { Cercanía }=72 \\
\text { Lejanía }=106 \\
\text { *laro } \\
\text { Cercanía }=71 \\
\text { Lejanía }=107\end{array}$ \\
\hline
\end{tabular}

Fuente: elaboración propia. 
Los indicadores posicionales de rango y grado de cercanía tanto para la dimensión de acceso y la equidad indican que los actores de mayor conectividad y representatividad en la red son los actores reguladores MinTIC, CRC, SIC, DNP, ANE y ANTV con 77 relaciones y $100 \%$ de afinidadconectividad en la red. El grado de intermediación evidencia que los actores puente con 9.5 y 0,3\% (dimensión de acceso) y con 119.6 y 4\% (dimensión de equidad) son dos actores reguladores MinTIC, CRC, SIC, DNP, ANE y ANTV

El Estado tiene una posición representativa en las redes de acceso y equidad por sus respectivos actores reguladores, pero no es el único actor relevante, por la existencia de actores regulados y no regulados que influyen de manera directa en las redes por sus capacidades y recursos reflejados por su rango, grado de intermediación y grado de cercanía.

En la dimensión del acceso, por los actores no regulados están la UTI, Cepal y OEA; y por los actores regulados están Telefónica-Movistar, Tigo-Une y Claro. En la dimensión de la equidad, por los actores regulados están la UTI, y por los actores regulados están Telefónica-Movistar, Tigo-Une y Claro.

El análisis posicional de la red muestra un Estado Promotor y mediador [132] —MinTIC, DNP, CRC, SIC, ANTV, ANE—, que por la dinámica de la red debe cooperar con: a) actores regulados —Claro, Telefónica-Movistar y Tigo-Uney b) actores no regulados — UTI, Cepal, OEA—, sustentando en el rango, grado de intermediación y grado de cercanía.

Al profundizar el análisis posicional de acceso y equidad, no solo teniendo en cuenta la nominación de actores reguladores, regulados y no regulados, sino la nominación del rol en el sector, se delimitan tendencias fuertes y definidas del sector de las TIC 2009-2018 en orden jerárquico:

$\square$ La representatividad de los actores estatales como centralidad de las redes - MinTIC, DNP, CRC, SIC, ANTV, ANE-.

$\square$ La jerarquía internacional de la Unión Internacional de Telecomunicaciones como organización mundial especializada en TIC.

El oligopolio de los operadores internacionales de TIC —Claro, Telefónica-Movistar y Tigo-Une-, y también su participación activa en procesos de responsabilidad social corporativa.

$\square$ La membresía de actores regulados y no regulados —Asomovil, CCIT, Fedesot, Andesco, CCCE, Asiet-. 
Los principios rectores de política pública de acceso y equidad como dimensiones...

La participación activa de centros de pensamiento de orden nacionalprivado —Fedesarrollo, Cintel, Aciem y Corporación Colombia Digital_, y de orden internacional-privado —Cepal, CAF, OCDE y Citel—.

$\square$ Organismos multilaterales de política pública —BID, BM, OMC, Unesco, OEA-.

Los servicios de comunicación audiovisual —Google, Facebook, Netflix y Twitter-.

Las empresas de fabricación e innovación —Ericsson, Microsoft, Sony, Apple, IBM, Huawei-.

$\square$ Las empresas licitadores y ganadoras de proyectos de TIC en infraestructura y apropiación de contenidos digitales -Energía Integral andina, Total Play, Anditel, Grupo Hispasat, NEC de Colombia , Cisco , ATC y BT-.

\section{Conclusión}

La estimación y análisis de la estructura en red de los principios rectores de acceso — universalidad — y equidad como dimensiones de red de política pública en Colombia 2009-2018, determinan y contrastan una política pública de regulación de TIC muy fuerte en la promoción y el desarrollo de la sociedad de la información-sociedad del conocimiento en materia de acceso, pero medianamente definida en innovación social, inclusión social, apropiación del conocimiento tecnológico por parte de comunidades marginadas, desarrollo tecnológico y potencialización de capacidades regionales y territoriales en materia de equidad.

Esto marca un derrotero de ajustes que se deben realizar al marco regulatorio del sector, en cuanto a: a) mayor circulación y aprovechamiento de datos abiertos que se conviertan en información digital recogida por organizaciones privadas o públicas, difundidas en formatos de fácil acceso; b) mecanismos institucionales para la formalización en red de actores regulados y no regulados que se dinamicen con las membresías existentes que representan a los actores regulados y no regulados del sector; y c) proyectos y programas de equidad como la universalización de componentes educativos digitales, reducción de la brecha entre la ciudadanía digital y los nativos digitales, ruralidad digital y productiva, herramientas digitales aplicadas a la conservación del ambiente, información y bases de datos en tiempo real, 
y plataformas digitales y de fácil entendimiento como bienes públicos rivalidad y no exclusión-.

Los principios rectores de acceso y equidad como dimensiones de red demarcan una política pública de alta conectividad, multicéntrica y de riqueza heterogénea, y la dinámica regulatoria en materia de acceso y equidad demarca actores de orden Estatal, centralizados y conectados entre sí, con derroteros claros en la transacción de recursos y afinidad de interrelaciones con un alto grado de interdependencia con los actores regulados y no regulados, que se cristalizan en programas y proyectos de gran temporalidad.

Lo anterior permite concluir que la red de política pública de regulación de las TIC en Colombia 2009-2018 responde a una red temática -issue networks - porque: a) el Estado ya no es el único agente proveedor de servicios públicos domiciliarios y no domiciliarios en Colombia; b) el marco normativo de las TIC en Colombia incentiva la competencia y la inversión extranjera; c) la eficiencia de las TIC que inciden en la competitividad, productividad y los acuerdos de los actores reguladores e institucionales; d) el acceso es la representatividad de la maximización de los intereses de los actores regulados y no regulados por la sostenibilidad de recursos en las redes; e) la equidad [134] es un proceso de directrices institucionales de los actores reguladores y la responsabilidad social corporativa de actores regulados y no regulados.

Existe una gran diferencia entre acceso y equidad como principios rectores, porque la orientación de la política busca el desarrollo de un ecosistema digital basado en la oferta — servicios e infraestructura - y la demanda usuarios y aplicaciones-. En primer lugar, los servicios e infraestructura están representados por un grupo triangular muy fuerte, tipo cartel u oligopolio Claro, Movistar, Tigo-Une-, el cual tiene alianza estratégica con la compañía en infraestructura American Tower Corporation, sustentada por la venta de la infraestructura y las redes que montaron desde 1994, cuando se firmaron los contratos de concesión con el Gobierno colombiano. Esta transacción se dio con el fin de soportar el crecimiento de la red inalámbrica por medio de contratos de arriendo a largo plazo y contratos de construcción, costo que se refleja de manera indirecta en los precios del mercado.

En segundo lugar, los usuarios tienen una representatividad que no actúa en forma de subred, sino por la lógica institucional y organizacional de la Superintendencia de Industria y Comercio (SIC), la Contraloría y la Procuraduría General de la Nación. Existen otros actores del tercer sector, 
como la Fundación Karisma y la Asociación Colombiana de Usuarios de Internet (ACUI), que carecen de burocracia especializada que no les permite generar un debate profundo sobre el desarrollo del sector y deben hacer alianzas con centros de pensamiento como Cintel, Corporación Colombia Digital y Cámara Colombiana de Informática y Telecomunicaciones (CCIT), en asocio con Fedesarrollo, los cuales apoyan los principales operadores.

El principio rector de equidad, al medirse como una dimensión de red de política pública, presenta una diferencia alta con el principio rector de acceso. Se puede afirmar que es un proceso medianamente importante y residual para los actores regulados y no regulados, eso lo evidencia las gráficas y los datos estructurales y posicionales de las redes en cuanto a la centralidad de los actores reguladores y logros de la política pública de TIC en Colombia 2009-2018.

Los actores reguladores en el acceso como dimensión de red son nodos de relevancia y tránsito entre los demás actores, con muy poca dispersión con los demás actores de la red; por el contario, los actores reguladores en la equidad son nodos de alta jerarquía y centralidad, con una dispersión notable con los demás actores de la red. Los actores regulados y no regulados en el acceso como dimensión de red son nodos que relejan una conectividad alta y muy poca dispersión entre ellos, lo cual los hace relevantes en la dinámica en red propia del sector; en cambio, en la equidad como dimensión de red son nodos que relejan una conectividad media y una dispersión alta entre ellos, lo cual los hace poco relevantes.

Es importante analizar que dentro de la red hay ciertos actores que participan, pero hay que determinar si todos los actores tienen el mismo poder, esto depende de cómo se estructuran las relaciones entre los poderes públicos y los poderes privados, y los recursos que tienen las organizaciones que participan. Si se pertenece a la industria TIC se tiene mucho poder, porque se posee información que el actor público necesita, esto genera poder para negociar o interactuar. El contexto de una dinámica en red no institucionalizada afianza rentas de información, autonomía y movilidad en recursos, contratación, competitividad por producción intelectual y de conocimiento en forma de consultoría de orden nacional e internacional, subredes de innovación y producción de TIC no reguladas pero legitimadas por la dinámica de los actores en la construcción y evaluación del costobeneficio de las conexiones. 


\section{Referencias bibliográficas}

1. Aguirre, Julio L. (2014). Actores, relaciones y estructuras: introducción al análisis de redes sociales. Hologramática, 2 (20), pp.161-187.

2. Aubin, David \& Verhoest, Koen (eds.). (2014). Multilevel Regulation in Telecommunications. Adaptive Regulatory Arrangements in Belgium, Ireland, the Netherlands, and Switzerland. Basingstoke: Palgrave Macmillan.

3. Barozet, Emmanuelle. (2002). La teoría de redes y sus aplicaciones en ciencia Política: una herramienta heurística. Revista de Ciencia Política, xxII (1), pp. 17-38.

4. Borgatti, S. P., Everett, M. G. \& Freeman, L. C. (2002). Ucinet for Windows: Software for Social Network Analysis (6.0). [Software de cómputo]. Harvard: Analytic Technologies.

5. Cárdenas, Julián. (2012a). Varieties of Corporate Networks: Network Analysis and fsQCA. International Journal of Comparative Sociology, 53 (4), pp. 298-322. https://doi.org/10.1177/0020715212460257

6. Cárdenas, Julián. (2012b). La organización en red del poder corporativo: una tipología de redes corporativas. Revista Internacional de Sociología, 71 (1), pp. $77-$ 105. https://doi.org/10.3989/ris.2010.09.04

7. Cárdenas Julián. (2014a). Are Latin America's Corporate Elites Transnationally Interconnected? A Network Analysis of Interlocking Directorates. Global Networks. A Journal of Transnational Affairs, 15 (4), pp. 424-445. https://doi.org/10.1111/ [136] glob.12070

8. Cardenas, Julián. (2014b). El poder económico mundial. Análisis de redes de interlocking directorates y variedades de capitalismo. Madrid: CIS.

9. Cárdenas, Julián. (2016). Why do Corporate Elites form Cohesive Networks in Some Countries, and Do Not in Others? Cross-National Analysis of Corporate Elite Networks in Latin America. International Sociology, 31 (3), pp. 341-363. https://doi. org/10.1177/0268580916629965

10. Eisenhardt, Kathleen M. (1989). Building Theories from Case Study Research. Academy of Management Review, 14 (4), pp. 532-550. https://doi.org/10.5465/ amr.1989.4308385

11. Emerson, Richard M. (1962). Power-Dependence Relations. American Sociological Review, 27 (1), pp. 31-41. https://doi.org/10.2307/2089716

12. Garrido, Francisco J. (2001). El análisis de redes en el desarrollo local. En: Montañés Serrano, Manuel; Rodríguez-Villasante Prieto, Tomás y Martín Gutiérrez, Pedro (coords.). Prácticas locales de creatividad social (pp. 67-89). Madrid: El Viejo Topo.

13. González, Camilo Ignacio. (2017). Measuring and Comparing the Distribution of Decision-Making Power in Regulatory Arrangements of the Telecommunication Sector in Latin America. Journal Utilities Policy, 49, pp. 145-155. https://doi. org/10.1016/j.jup.2017.04.002 
Los principios rectores de política pública de acceso y equidad como dimensiones...

14. González, Camilo Ignacio; Nurul Amin, Md \& Verhoest, Koen. $\left(2015,12^{\text {th }}\right.$ June). Measuring and Explaining Coordination in Multilevel and Multi-Actor Regulatory Arrangements of Liberalized Telecommunication Markets in Europe, Latin America, and South Asia. 4th Conference on the Regulation of Infrastructures: Regulating Network Industries in Emerging Countries. Florence School of Regulation, Robert Schuman Centre for Advanced Studies, European University Institute Conference Room, Villa La Fonte.

15. González Builes, Nicolás. (2014). La teoría de redes sociales y las políticas públicas. Una aproximación al debate teórico y a las posibilidades de intervención en realidades sociales. Revista Forum. 2 (6), pp. 81-97.

16. Grau Solés, Marc; Íñiguez Rueda, Lupicinio y Subirats, Josep. (2010). La perspectiva sociotécnica en el análisis de políticas públicas. Psicología Política, 41, pp. 61-80.

17. Guerra de la Espriella, María del Rosario y Oviedo Arango, Juan Daniel. (2011). De las telecomunicaciones a las TIC: Ley de TIC de Colombia (L1341/09). Estudios y Perspectivas, 22. Recuperado de http://www.telebrasil.org.br/component/ docman/doc_download/1617-de-las-telecomunicaciones-a-las-tic-ley-de-tic-decolombia-I1341-09? Itemid $=930$

18. Jordana, Jacint. (2009). Examinando las redes de actores en el análisis de las políticas públicas: debate teórico y técnicas cuantitativas. Gestión y Análisis de Políticas Públicas, 1, pp. 9-15.

19. Jordana, Jacint \& Sancho, David (eds.). (2004). Regulatory Designs, Institutional Constellations and the Study of the Regulatory State. In: The Politics of Regulation: Institutions and Regulatory Reforms for the Age of Governance (pp. 296319). Cheltenham: Edward Elgar.

20. Jordana, Jacint \& Levi-Faur, David. (2005). The Diffusion of Regulatory Capitalism in Latin America: Sectoral and National Channels in the Making of a New Order. The ANNALS of the American Academy of Political and Social Science, 598 (1), pp. 102-124. https://doi.org/10.1177/0002716204272587

21. Katz, Raúl. (2015). El ecosistema y la economía digital en América Latina. Barcelona: Fundación Telefónica.

22. Kuz, Antonieta; Falco, Mariana y Giandini, Roxana. (2016). Análisis de redes sociales: un caso práctico. Computación y Sistemas, 20 (1), pp. 89-106. http://dx.doi. org/10.13053/cys-20-1-2321

23. Langley, Ann \& Royer, Isabelle. (2006). Perspectives on Doing Case Study Research in Organizations. M@n@gement, 9 (3),pp. 81-94. https://doi.org/10.3917/ mana.093.0081

24. Latour, Bruno. (2005). Reassembling the Social: An introduction to ActorNetwork-Theory. Oxford: Oxford University.

25. Lopasso, Guilherme. (2011). Como lidiar con servicios Over-The-top. Ericsson $A B$. Recuperado de https://es.slideshare.net/EricssonLatinAmerica/ott-es 
26. Lozares, Carlos y Verd Joan Miquel. (2015). Bases socio-metodológicas del análisis de redes sociales. En: García Ferrando, Manuel; Alvira, Francisco; Alonso, Luis E. y Escobar, Rafael. Análisis de la realidad social. Métodos y técnicas de investigación (pp. 664-688). Madrid: Alianza.

27. Machín Ramírez, Juan. (2011). Redes sociales e incidencias en políticas públicas. Estudio comparativo México-Colombia. México D. F.: Centro Cáritas.

28. Musca, Geneviève. (2006). Une strategie de recherche processuelle: I'étude longitudinale de cas enchâsesés. M@n@gement, 9 (3), pp. 153-176. https://doi. org/10.3917/mana.093.0153

29. Nurul Amin, Md \& Verhoest, Koen (2016, 6-8 July). De-facto Coordination in Regulatory Decision-Making on Liberalized Telecommunications Sector in Bangladesh and Nepal: A Social Network Analysis. Regulatory Governance, Tilburg University.

30. Organisation for Economic Co-operation and Development (OECD). (2016). Broadband Policies for Latin America and the Caribbean. A Digital Economy Toolkit. Paris: OECD. Retrieved from http://www.oecd-ilibrary.org/ deliver/9789264251823-en.pdf?itemld =/content/publication/9789264251823en\&mimeType = application/pdf

31. Organización para la Cooperación y Desarrollo Económico (OCDE). (2014). Estudio de la OCDE sobre políticas y regulación de telecomunicaciones en Colombia. París: OECD. http://dx.doi.org/10.1787/9789264209558-es

[138] 32. Organización para la Cooperación y Desarrollo Económico (OCDE). (2015). Perspectivas de la OCDE sobre la economía digital 2015. París: OCDE. Recuperado de http://www.ccoo.es/7ca5782b36b4c532407d13dc6f4c4762000001.pdf

33. Patton, Michael Quinn. (2002). Qualitative Evaluation \& Research Methods. Thousand Oaks: Sage.

34. Rama, Paula y Luaces, Pilar. (2007, septiembre). Análisis de redes aplicado a la formación de la agenda pública en las conurbaciones gallegas: los casos de Vigo y A Coruña. ıx Congreso de la Federación Española de Sociología, Barcelona.

35. Ramilo Araujo, María del Carmen. (2010). Políticas públicas, instituciones y actores para la promoción de la sociedad de la información y/o del conocimiento: un análisis comparado de Catalunya y Euskadi. (Tesis doctoral). Universidad del País Vasco. https://doi.org/10.24965/gapp.v0i1.415

36. Rodríguez, Josep. (2005). Análisis estructural y de redes. Madrid: CIS.

37. Scharpf, Fritz W. (1997). Games Real Actors Play: Actor-Centred Institutionalism in Policy Research. Boulder: Westview.

38. Serna González, Luis Antonio. (2012). Análisis estructural de una red temática de política pública: el caso del Comité Técnico Interinstitucional de Investigación en Salud. (Tesis de maestría). El Colegio de San Luis, San Luis Potosí.

39. Tabarquino Muñoz, Raúl Andrés. (2015). La red de política pública de TIC en Colombia. Actores reguladores y principales operadores. Estudios Políticos (Universidad de Antioquia), 46, pp. 221-241. 
40. Tabarquino Muñoz, Raúl Andrés. (2016). El análisis organizacional y de política pública a partir del enfoque de redes. Tendencias, xVII (2), 79-92. https://doi. org/10.22267/rtend.161702.4

41. Tabarquino Muñoz, Raúl Andrés. (2018). La red de política pública de regulación del servicio público de las tecnologías de la información y las comunicaciones (TIC) en Colombia 2009-2016: el acceso (universalidad) y la equidad como principios rectores. (Tesis doctoral). Universidad del Valle, Cali.

42. Valencia Tello, Diana Carolina. (2015). Implementación de tecnologías de la información y las comunicaciones (TIC) en Colombia. Revista de Derecho, Comunicaciones y Nuevas Tecnologías, 14. http://dx.doi.org/10.15425/ redecom.14.2015.07

43. Varela Barrios, Edgar. (2015). Los retos de las políticas públicas de provisión de las Tecnologías de la información y las comunicaciones (TIC) en Colombia Universalidad en el acceso y equidad como principios constitucionales Versus las asimetrías de poder e información y la captura de rentas por los operadores empresariales. Manuscrito inédito.

44. Verd Pericás, Jhoan Miquel y Martí Olivé, Joel. (1999). Muestreo y recogida de datos en el análisis de redes sociales. Qüestiió, 23 (3), p. 507-524.

45. Wasserman, Stanley y Fauts, Katherine. (2013). Análisis de redes sociales. Métodos y aplicaciones. Madrid: CIS.

46. Yin, Robert. (2003). Case Study Research. Thousand Oaks: Sage.

47. Zurbriggen, Cristina. (2004). Redes, actores e instituciones. Revista del CLAD Reforma y Democracia, 30, pp. 167-188. 